\title{
ECOFISIOLOGIA DA GERMINAÇÃO DE FEDEGOSO Senna obtusifolia (L.) H. S. IRWIN \& BARNEBY
}

Sara Bezerra Bandeira ${ }^{1}$, Gessica Hashimoto de Medeiros $^{1}$, André Amaral da Silva ${ }^{2}$, Iranete Reis Saraiva ${ }^{3}$, Priscila Bezerra de Souza ${ }^{1}$, Eduardo Andrea Lemus Erasmo ${ }^{1}$

Universidade Federal do Tocantins - UFT, ${ }^{1}$ Pós-Graduação em Ciências Florestais e Ambientais. Curso de Agronomia. Curso de Ciências Biológicas

\section{RESUMO}

Objetivou-se com esse trabalho avaliar a germinação das sementes de Senna obtusifolia (L.) H. S. Irwin \& Barneby em diferentes condições ambientais. Para isso, foram realizados quatro experimentos: 1 avaliação de diferentes métodos de superação de dormência (escarificação manual com lixa; imersão em ácido sulfúrico por 1,5 e 10 minutos; imersão em água quente $\left(95^{\circ} \mathrm{C}\right)$ por 1,5 e 10 minutos; e tratamento controle); 2 - avaliação da germinação em diferentes temperaturas (20, 25, 30 e 35 ㅇ) ; 3 - influência de soluções aquosas com diferentes níveis $\mathrm{pH}(3,0 ; 5,0 ; 7,0 ; 9,0$; e 11,0) na germinação; 4 - influência dos sais $\mathrm{NaCl}, \mathrm{KCl}$ e $\mathrm{CaCl}_{2}$ nas concentrações $0,25,50,75$ e $100 \mathrm{mM}$ no processo germinativo. Onde todos os tratamentos foram testados no fotoperíodo de 12 horas. Os parâmetros avaliados foram à porcentagem de germinação e IVG. O delineamento experimental utilizado foi o inteiramente casualizado, com quatro repetições de 50 sementes para cada tratamento. Os dados dos tratamentos de superação de dormência foram submetidos ao teste de médias através do software Sisvar, pelo teste Tukey a nível de $5 \%$ de probabilidade. Os dados de temperatura, $\mathrm{pH}$ e estresse salino foram submetidos à análise de regressão utilizando o software Sigmaplot 10.0 e o modelo de regressão escolhido foi baseado na significância dos coeficientes da equação de regressão e determinação a $5 \%$ de probabilidade. Os resultados mostraram que o melhor método para superação da dormência de sementes foi à imersão ácido sulfúrico por 10 minutos. A temperatura ótima para porcentagem de germinação e IVG foi de $25^{\circ} \mathrm{C}$. A germinação ocorreu em todas as faixas de $\mathrm{pH}$ analisadas, porém decrescendo com o aumento do $\mathrm{pH}$. $\mathrm{O}$ tratamento realizado com estresse salino afetou negativamente a germinação das sementes, tendo os piores resultados na solução salina de $\mathrm{CaCl}_{2}$ na concentração de $50 \mathrm{mM}$.

Palavras-chave: Emergência; pH; salinidade; superação de dormência; temperatura.

\section{GERMINATION ECOPHYSIOLOGY OF FEDEGOSO Senna obtusifolia (L.) H. S. IRWIN \& BARNEBY}

\begin{abstract}
The objective of this work was to evaluate the germination of Senna obtusifolia (L.) H. S. Irwin \& Barneby seeds in different environmental conditions. Four experiments were carried out: 1 - evaluation of different methods to overcome seed dormancy (manual scarification with sandpaper;

immersion in sulfuric acid for 1,5 and 10 minutes; immersion in hot water $\left(95^{\circ} \mathrm{C}\right)$ for 1,5 and 10 minutes and control treatment); 2 - evaluation of germination at different temperatures $\left(20,25,30\right.$ and $\left.35^{\circ} \mathrm{C}\right) ; 3-$ Influence of aqueous solutions with different $\mathrm{pH}$ levels (3.0, 5.0, 7.0, 9.0 and 11.0) on germination; and 4 influence of salts $\mathrm{NaCl}, \mathrm{KCl}$ and $\mathrm{CaCl}_{2}$ at concentrations of $0,25,50,75$ and $100 \mathrm{mM}$ in the germination process. Where all treatments were tested in the 12-hour photoperiod. The evaluated parameters were the percentage of germination and IVG. The experimental design was completely randomized, with four replicates of 50 seeds for each treatment. The data of the dormancy surpass treatments were submitted to the means test using the Sisvar software, using the Tukey test at a $5 \%$ probability level. The results showed that the best method to overcome seed dormancy was to immersion sulfuric acid for 10 minutes. The optimum temperature for percentage of germination and IVG was $25^{\circ} \mathrm{C}$. Germination occurred in all pH ranges analyzed, but decreasing with increasing $\mathrm{pH}$. The treatment with saline stress negatively affected seed germination, with the worst results in $50 \mathrm{mM} \mathrm{CaCl} 2$ salt solution.

Key words: Emergency; overcome dormancy; $\mathrm{pH}$; salinity; temperature.
\end{abstract}




\section{INTRODUÇÃO}

Conhecida popularmente como fedegoso, mata-pasto, pau-verde ou mamangá, a Senna obtusifolia (L.) H.S.Irwin \& Barneby é uma espécie subarbustiva anual que se desenvolve de forma espontânea em todo o Brasil, vegetando em áreas com lavouras anuais e perenes, áreas ocupadas com fruticultura, pastagens, terrenos baldios e bordas de fragmentos florestais (MOREIRA; BRAGANÇA, 2011). A espécie S. obtusifolia (L.) H.S.Irwin \& Barneby possui alto potencial produtivo, produzindo grandes quantidades de frutos com sementes deiscentes de fácil coleta em áreas abandonadas e bordas de fragmentos de diversos ecossistemas, entretanto, muitas sementes dessa espécie não germinam ao caírem no solo embora viáveis (TOPANOTTI et al., 2014). De acordo com Vivian et al. (2008), existem alguns fatores associados ao ambiente que afetam o processo germinativo como a falta de água ou o seu excesso, temperaturas acima ou abaixo do ideal para a germinação e desenvolvimento da espécie ou, ainda, a ausência de luz. Vivian et al. (2008), ainda relata que outras propriedades intrínsecas das sementes constituem a segunda e mais importante razão que impede a germinação, representadas por características do embrião e demais estruturas incluindo o endosperma, o tegumento, ou mesmo a ação de partes dos frutos.

Souza et al. (2008), afirmam que sementes da família Fabaceae apresentam dormência devido à impermeabilidade do seu tegumento a água, sendo que dentro do gênero Senna existe algumas espécies herbáceas que apresentam sementes dormentes, dentre elas, tem-se as espécies $S$ siamea (Lam.) H. S. Irwin \& Barneby e S. spectabilis (DC) Irwin \& Barneby , o que torna temporariamente difícil a germinação, prolongando a viabilidade das sementes por mais tempo.

A dormência apresenta aspectos positivos em termos ecológicos em relação à sobrevivência das espécies em condições naturais, por ser uma característica evolutiva, pois distribui a germinação ao longo do tempo e permite que a germinação ocorra somente em condições favoráveis à sobrevivência das plântulas (DUTRA et al., 2007). Porém, a dormência de espécies de plantas daninhas pode ser um fator que dificulta a realização de pesquisas direcionadas ao manejo e ao controle destas espécies em áreas agrícolas. Desta forma, métodos eficazes de superação da dormência promovem uniformidade e rapidez na germinação (ERASMO et al., 2008).

Conforme Carvalho e Nakagawa (2012) o controle aparente de todas as plantas daninhas de um campo não é suficiente para erradicar a espécie invasora, pois as sementes dormentes podem permanecer armazenadas no solo e a germinação é distribuída ao longo do tempo.

Além da dormência, existem outros fatores que têm sido apontados como controladores da germinação das sementes no campo, que estão relacionados às condições de solo, como $\mathrm{pH}$ e nível salino, e outros relativos ao clima, como temperatura e luz, entretanto, variações na intensidade de resposta são observadas em função da espécie estudada (GORAI; NEFFATI, 2007).

Segundo Vivian et al. (2008), a compreensão do comportamento da germinação das sementes de espécies de plantas daninhas contribuem significativamente para as técnicas de controle e manejo a serem utilizadas.

Dessa forma, devido à ausência de informações sobre o manejo e análise de sementes, de modo a fornecer dados que determinem suas características físicas e fisiológicas (LIMA et al., 2006) e considerando a ausência de informações com S. obtusifolia (L.) H.S.Irwin \& Barneby em ambientes com diferentes $\mathrm{pH}^{\prime}$ s e ambientes salinos, avaliar o melhor método para superação da dormência, a interferência da temperatura, do $\mathrm{pH}$ e do estresse salino sobre a germinação de $S$. obtusifolia (L.) H.S.Irwin \& Barneby.

\section{MATERIAL E MÉTODOS}

O presente estudo foi conduzido no Laboratório de Sementes de Ecofisiologia e Manejo de Plantas Daninhas da Universidade Federal do Tocantins, Campus Universitário de Gurupi, localizado na região sul do Estado do Tocantins a $280 \mathrm{~m}$ de altitude, sob as coordenadas $11^{\circ} 43^{\prime} \mathrm{S}$ e $49^{\circ} 04^{\prime} \mathrm{W}$. O Clima segundo a classificação de Köppen é do tipo Tropical de savana (Aw), úmido com pequena deficiência de água no inverno (PEEL et al., 2007). A temperatura média anual é de $29,5^{\circ} \mathrm{C}$ e precipitação média anual de $1.804 \mathrm{~mm}$, sendo verão chuvoso, inverno seco e elevado déficit hídrico entre os meses de maio a setembro (VAZDE-MELO et al., 2010). 
As sementes de Senna obtusifolia (L.) H.S.Irwin \& Barneby foram coletadas em agosto 2015 em uma área de pastagem localizada na fazenda experimental da Universidade Federal do Tocantins, campus de Gurupi, em um número mínimo de 10 plantas-mãe (lote), posteriormente foram transportadas até o Laboratório de Sementes de Ecofisiologia e Manejo de Plantas Daninhas da UFT, campus de Gurupi, onde foram beneficiadas e selecionadas manualmente, descartando-se as que apresentavam injurias ou estavam deformadas.

Foram realizados quatro experimentos, visando avaliar o melhor método de superação de dormência (ácido sulfúrico, água quente e lixa), influência da temperatura, estresse salino e $\mathrm{pH}$ na germinação de sementes de $S$. obtusifolia (L.) H.S.Irwin \& Barneby.

Para todos os experimentos, foi utilizado o delineamento experimental inteiramente casualizado, com quatro repetições de 50 sementes para cada tratamento. Os dados de superação de dormência foram submetidos a análise de variância através do Software Sisvar e comparadas pelo teste Tukey a $5 \%$ de probabilidade. Já os dados obtidos nos experimentos de temperatura, $\mathrm{pH}$ e estresse salino foram submetidos à análise de regressão utilizando o software Sigmaplot 10.0 e o modelo de regressão escolhido foi baseado na significância dos coeficientes da equação de regressão e de determinação a $5 \%$ de probabilidade.

As sementes foram colocadas para germinar em placas de Petri sobre duas folhas de papel para germinação umedecidas com água quando submetidas à superação de dormência e com cada solução (de acordo com os tratamentos de cada experimento), na proporção de 2,5 vezes a massa do substrato seco (BRASIL, 2009) posteriormente as placas de Petri foram acondicionadas em câmaras de germinação com regime de luz (fotoperíodo) de 12/12 horas diurna/noturna.

\section{Superação da dormência}

Os

tratamentos

para superação de dormência foram constituídos por escarificação mecânica com lixa $n^{\circ} 80$; imersão em ácido sulfúrico concentrado a $98 \%$ por 1, 5 e 10 minutos; imersão em água quente $(100$ ㅇ) por 1,5 e 10 minutos e controle (sem tratamento).
Para os tratamentos com ácido sulfúrico, primeiramente as sementes foram colocadas em Becker com uma quantidade e ácido sulfúrico suficiente para cobrir as sementes com constante agitação com bastão de vidro, em seguida as sementes foram mergulhadas em um Becker contendo água e logo após com o auxilio de uma peneira foram lavadas em água corrente até a remoção completa do produto.

Após a aplicação dos tratamentos de superação da dormência as sementes foram tratadas com solução de hipoclorito de sódio a $2 \%$ por 3 minutos e logo após foram colocadas para germinar em placas de Petri sobre duas folhas de papel para germinação e posteriormente acondicionadas em germinador do tipo BOD com regime de luz de $12 \mathrm{~h}$, a uma temperatura de 25 ㅇ. . A partir do terceiro dia após instalação dos tratamentos, a germinação foi avaliada diariamente, considerando como germinada a semente cuja radícula atingiu $2 \mathrm{~mm}$ de comprimento.

Após a definição do melhor tratamento para a superação da dormência de sementes de S. obtusifolia, as sementes foram submetidas aos testes de temperatura, $\mathrm{pH}$ e estresse salino, nos quais foram avaliados \% de germinação e IVG.

\section{Temperatura}

O tratamento de superação de dormência que proporcionou maiores porcentagens de germinação foi utilizado para avaliar a influência da temperatura na germinação. Após a quebra de dormência, foram avaliadas as temperaturas constantes de $20,25,30$ e 35 ㅇ C, com fotoperíodo de $12 / 12$ horas.

$\mathrm{pH}$

A influência do $\mathrm{pH}$ sobre a germinação das sementes de Senna obtusifolia foi testada sob os valores de 3,$0 ; 5,0 ; 7,0 ; 9,0$; e 11,0. Foi utilizado para ajustar o $\mathrm{pH}$ aos valores referidos acima, hidróxido de potássio $(\mathrm{KOH})$ ou ácido clorídrico $(\mathrm{HCl})$ à água destilada, em quantidade suficiente para elevar ou baixar $\mathrm{o} \mathrm{pH}$, sendo aferido com auxílio de um pHmetro (MAYEUX; SCIFRES, 1978).

\section{Estresse salino}

$\mathrm{Na}$ análise dos efeitos da salinidade, preparou-se soluções aquosas de cloreto de potássio $(\mathrm{KCl})$, cloreto de cálcio $\left(\mathrm{CaCl}_{2}\right)$ e cloreto de sódio ( $\mathrm{NaCl}$ ) nas concentrações de 25, 50, 75 e $100 \mathrm{mM}$ além da testemunha que foi umedecida 
apenas com água $(0 \mathrm{mM}))$ todas com quatro repetições de 50 sementes respectivamente.

Avaliou-se a porcentagem de germinação e o índice de velocidade de germinação, onde a germinação foi avaliada diariamente a partir do terceiro dia após a instalação dos tratamentos usando como critério a protrusão da radícula ( 2 $\mathrm{mm}$ ). As velocidades de germinação foram calculadas pela expressão:

$$
\mathrm{IVG}=\left(\frac{\mathrm{G} 1}{\mathrm{~N} 1}\right)+\left(\frac{\mathrm{G} 2}{\mathrm{~N} 2}\right)+\ldots+\left(\frac{\mathrm{Gn}}{\mathrm{Nn}}\right)
$$

Onde:

G: número de plântulas cuja radícula atingiu 2 $\mathrm{mm}$ de comprimento, computadas na primeira contagem, na segunda contagem, ..... na última contagem.

$\mathrm{N}$ : número de dias da semeadura à primeira, à segunda, ..., à última contagem.

\section{RESULTADOS E DISCUSSÃO Superação da dormência}

Entre todos os tratamentos avaliados para promover a superação da dormência das sementes de S. obtusifolia (L.) H. S. Irwin \& Barneby, constatou-se que o uso de ácido sulfúrico concentrado a $98 \%$ com exposição das sementes durante 10 minutos proporcionou maior germinação (porcentagem e índice de Velocidade de Germinação - IVG) em relação aos demais tratamentos. Porém, não apresentou diferença significativa quando comparado aos tratamentos com imersão das sementes em água quente durante 5 e 10 minutos (Tabela 1).
Ao analisar a imersão de sementes em água quente observou-se que 0 valor de germinação de sementes imersas por 1 minuto diferiu estatisticamente dos demais tratamentos (Tabela 1).

Em relação à imersão das sementes em ácido sulfúrico (Tabela 1), pode-se observar que a menor média de germinação foi obtida com a imersão por 1 minuto (31\%). Sendo que a medida que houve aumento do tempo de imersão, ocorreu acréscimo percentual da germinação, de forma que o maior percentual de germinação foi verificado com a imersão de sementes por 10 minutos (90\%). O tratamento com ácido sulfúrico por um minuto não apresentou resultados satisfatórios, pois à medida que se aumentava o tempo de imersão em ácido sulfúrico, também aumentava a degradação do tegumento da semente. Dutra et al. (2007), ao trabalharem com sementes de Senna siamea (Lam.) H. S. Irwin \& Barneby, observaram que havia aumento da germinação com exposição das sementes em ácido sulfúrico por um período de até 30 minutos, sendo a utilização de ácido sulfúrico um dos melhores métodos para superação de dormência das sementes dessa espécie. .

Os métodos de imersão de sementes em ácido sulfúrico concentrado a $98 \%$ durante 1 minuto e a escarificação mecânica com lixa $n^{\circ} 80$ foram os menos eficazes na superação de dormência das sementes de S.obtusifolia (L.) H. S. Irwin \& Barneby com valores entre 31 e $39 \%$ de germinação, respectivamente (Tabela 1).

Tabela 1. Germinação (\%) de sementes de Senna obtusifolia (L.) H. S. Irwin \& Barneby submetidas a diferentes tratamentos de superação de dormência.

\begin{tabular}{ccc}
\hline Tratamentos & Germinação (\%) & IVG \\
\cline { 1 - 1 } AQ1 & $44,00 \mathrm{~b}$ & $5,00 \mathrm{c}$ \\
Q5 & $79,00 \mathrm{a}$ & $9,50 \mathrm{~b}$ \\
AQ10 & $79,00 \mathrm{a}$ & $9,50 \mathrm{~b}$ \\
AS1 & $31,00 \mathrm{bc}$ & $2,50 \mathrm{c}$ \\
AS5 & $39,00 \mathrm{~b}$ & $3,00 \mathrm{c}$ \\
AS10 & $90,00 \mathrm{a}$ & $13,5 \mathrm{a}$ \\
Lixa & $32,00 \mathrm{bc}$ & $3,00 \mathrm{c}$ \\
Testemunha & $20,00 \mathrm{c}$ & $2,00 \mathrm{c}$ \\
\hline DMS & 15,82 & 3,42 \\
CV (\%) & 7,73 & 14,43 \\
\hline
\end{tabular}

Médias seguidas de mesma letra minúscula na coluna, não diferem estatisticamente entre si pelo teste de Tukey a $5 \%$ de probabilidade. AQ1 (água quente por 1 minuto); AQ5 (Água quente por 5 minutos); AQ10 (Água quente por 10 minutos); AS1 (Ácido Sulfúrico por 1 minuto); AS5 (Ácido Sulfúrico por 5 minutos); AS10 (Ácido Sulfúrico por 10 minutos). 
Piveta et al. (2010) ao avaliarem a germinação de S. multijuga (Rich.) H. S. Irwin \& Barneby, também indicaram a eficiência do ácido sulfúrico na superação de dormência dessa espécie. Assumpção e Perine (2016), observaram que $o$ potencial germinativo de $S$. occidentallis (L.) Link aumentou significativamente quando submetidos a escarificação química com ácido sulfúrico. No entanto, conforme Maranho e Paiva (2012), o sucesso nos tratamentos com ácido sulfúrico está relacionado com o tempo de exposição das sementes ao ácido e à espécie.

\section{Temperatura}

Após a superação da dormência de sementes com o tratamento que proporcionou maior porcentagem e índice de velocidade de germinação (imersão durante $10 \mathrm{~min}$ em ácido sulfúrico), foram realizados os testes para determinação da melhor temperatura para germinação de sementes de S. obtusifolia (L.) H. S. Irwin \& Barneby.

Os resultados obtidos para a porcentagem de germinação de sementes de $S$ obtusifolia (L.) H. S. Irwin \& Barneby submetidas a diferentes temperaturas (Figura 1) mostraram que a maior porcentagem de germinação foi obtida quando as sementes foram mantidas a temperatura de $25^{\circ} \mathrm{C}$, apresentando germinação acima de $80 \%$. Sendo que houve redução na germinação de sementes mantidas acima e abaixo de $25^{\circ} \mathrm{C}$, onde a menor taxa de germinação ocorreu na temperatura de $20^{\circ} \mathrm{C}$.

Parreira et al. (2011), obtiveram maior porcentagem de germinação na temperatura de $25^{\circ} \mathrm{C}$, em sementes de Momordica charantia L. O mesmo foi observado por Rodrigues et al. (2010) ao avaliarem a germinação de Stylosanthes macrocephala M. B. Ferreira \& S. Costa e S. capitata Vogel obtendo maiores valores de germinação na temperatura de $25^{\circ} \mathrm{C}$. Brancalion et al. (2010), ao analisarem a distribuição das temperaturas ótimas para a germinação das sementes de 272 espécies, afirmaram que a temperatura ótima de germinação da maioria das espécies do Cerrado, encontra-se em torno de $25^{\circ} \mathrm{C}$.

Figura 1. Germinação (\%) de sementes de Senna obtusifolia (L.) H. S. Irwin \& Barneby mantidas sob diferentes temperaturas contínuas com fotoperíodo de 12 após a superação da dormência em imersão por 10min em ácido sulfúrico

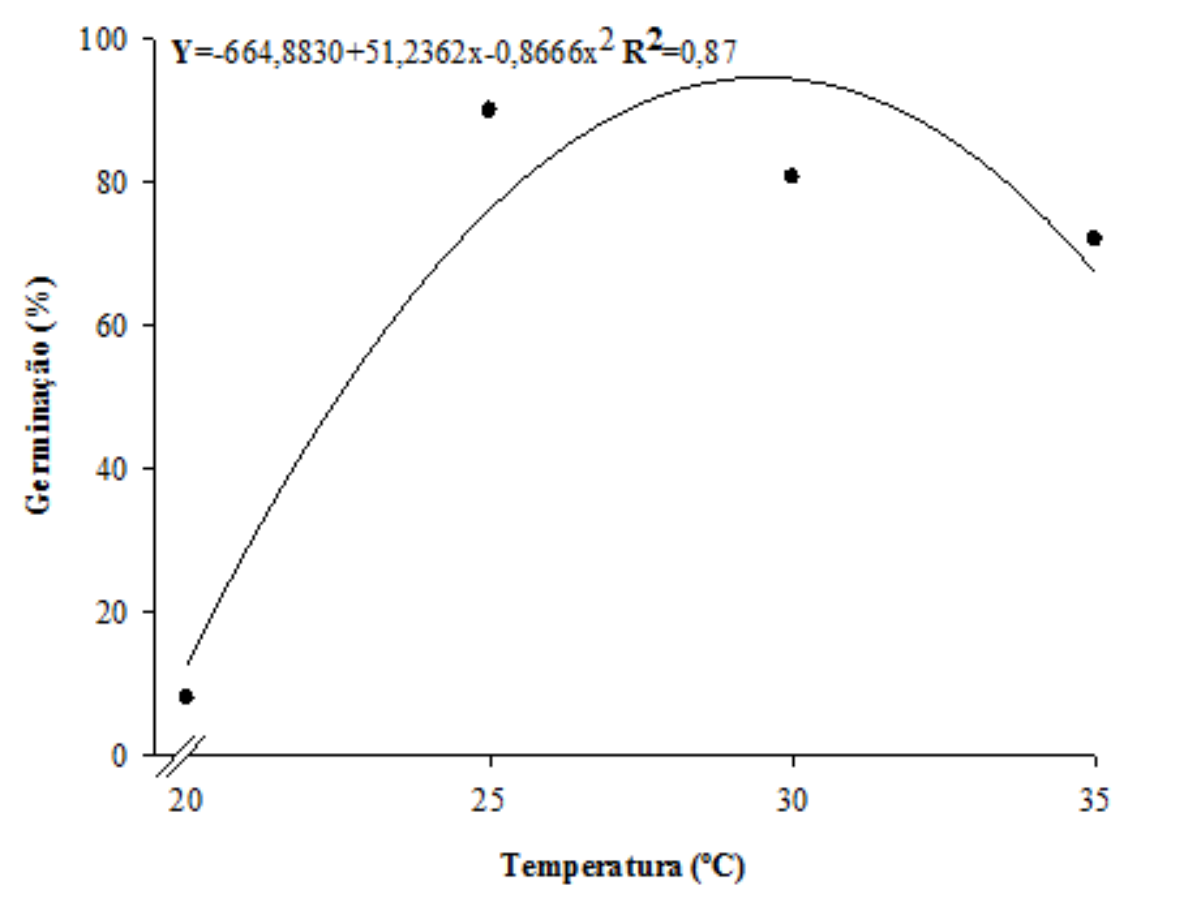

Os dados do Índice de Velocidade de Germinação (IVG) das sementes de sementes de
S. obtusifolia (L.) H. S. Irwin \& Barneby em diferentes temperaturas (Figura 2) mostraram 
relação com a porcentagem de germinação em análise de regressão quadrática, com aumento do IVG até a temperatura de $25{ }^{\circ} \mathrm{C}$ descendo em temperatura acima a esta.

Chiodini e Cruz-Silva (2013) em seu estudo também observaram maior taxa de germinação e IVG na temperatura de $25^{\circ} \mathrm{C}$, para Brachiaria brizantha (Hochst. ex A. Rich.) Stapf, indicando ser a temperatura mais indicada para a germinação da espécie.

Figura 2. Índice de velocidade de germinação (IVG) de sementes de Senna obtusifolia (L.) H. S. Irwin \& Barneby mantidas sob diferentes temperaturas contínuas com fotoperíodo de 12/12 horas diurna/noturna após a superação da dormência em imersão por $10 \mathrm{~min}$ em ácido sulfúrico pH

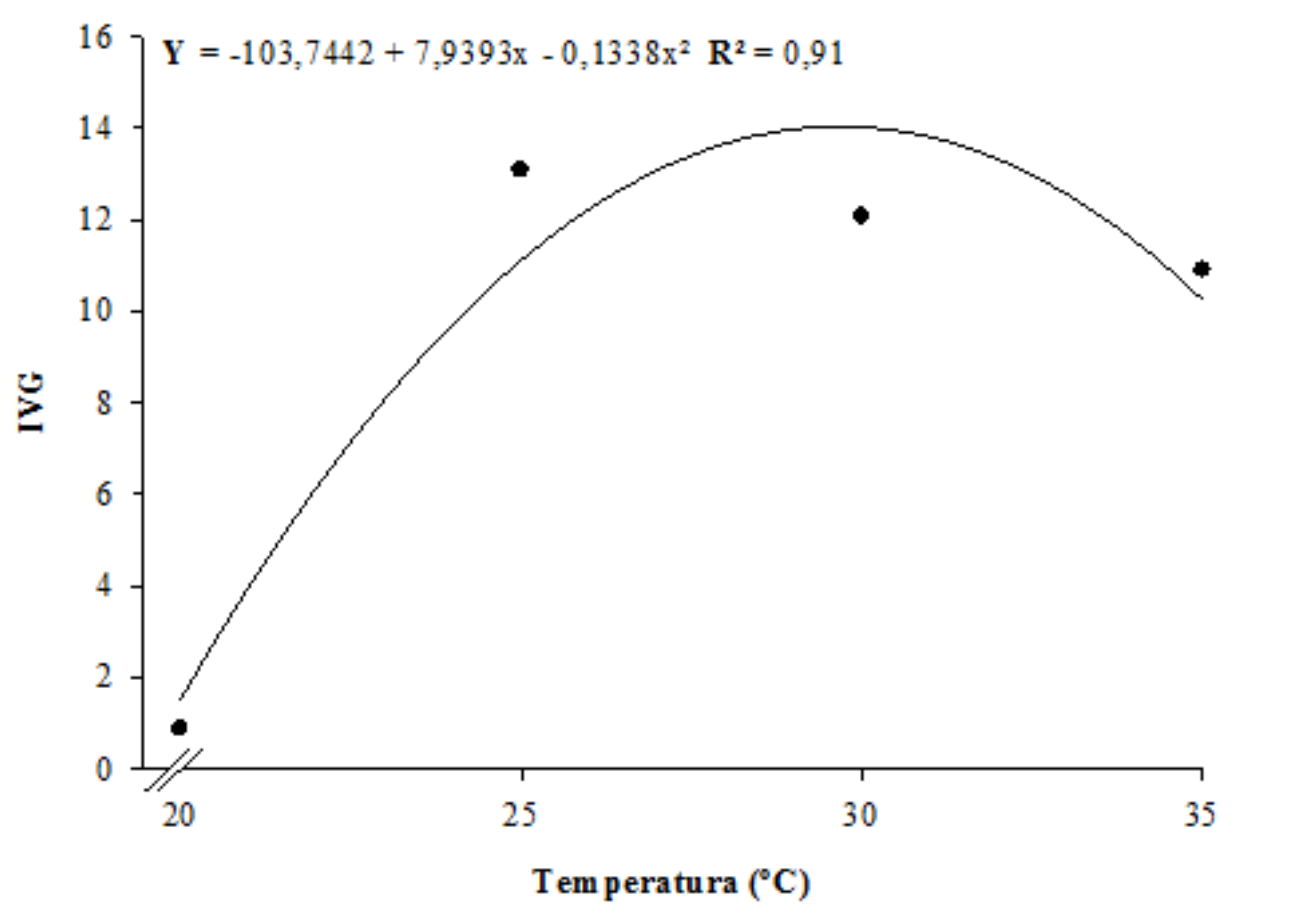

As sementes de S. obtusifolia (L.) H. S. Irwin \& Barneby germinaram em todas as faixas de $\mathrm{pH}$ testados, mas pode-se observar que a germinação foi maior em $\mathrm{pH}$ 3,0 e menor em $\mathrm{pH}$ 11,0, indicando um comportamento linear negativo, onde a porcentagem de germinação diminuiu gradativamente com o aumento do $\mathrm{pH}$. Ressaltando que deve-se levar em conta que há poucas informações na literatura sobre os efeitos do $\mathrm{pH}$ na germinação das sementes da família Fabaceae (Figura 3). Porém resultados semelhantes foram obtidos por Yamauti et al. (2012) trabalhando com sementes de
Synedrellopsis grisebachiie Hieron \& Kuntze obtiveram germinação nas faixas de $\mathrm{pH}$ de 3,0 a 11,0. De acordo com Arnon e Johnson (1942), as plantas podem suportar diversas faixas de $\mathrm{pH}$ em ambiente natural entre 4,0 e 8,0 fora desta faixa, concentrações elevadas de $\mathrm{H}^{+}$e $\mathrm{OH}^{-}$podem ser diretamente tóxicas às plantas. Conforme Yamauti et al. (2012), essa variação de tolerância pode variar de acordo com a espécie corroborando com os resultados obtidos no presente trabalho. 
Figura 3. Germinação (\%) de sementes de Senna obtusifolia (L.) H. S. Irwin \& Barneby submetidas a diferentes valores de $\mathrm{pH}$, avaliadas em fotoperíodo $12 / 12$ e temperatura de $25^{\circ} \mathrm{C}$

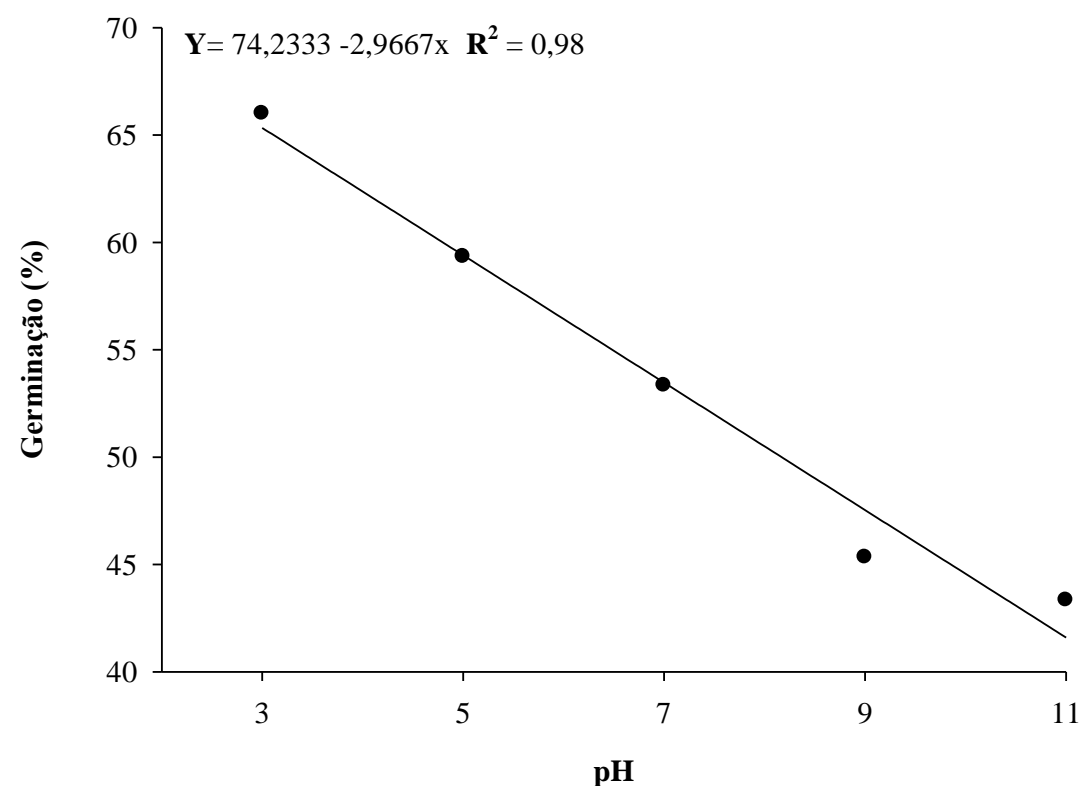

O índice de velocidade de germinação

(IVG) foi influenciado negativamente pelo aumento do $\mathrm{pH}$. O maior IVG foi obtido em condições de pH 3,0 (Figura 4). De acordo com
Yamashita et al. (2009), às variações de $\mathrm{pH}$ do meio em que se desenvolvem as plantas pode ser variável de acordo com a espécie.

Figura 4. Índice de velocidade de germinação (IVG) de sementes de Senna obtusifolia (L.) H. S. Irwin \& Barneby submetidas a diferentes valores de $\mathrm{pH}$, avaliadas em fotoperíodo $12 / 12$ e temperatura de $25^{\circ} \mathrm{C}$

\section{Estresse salino}

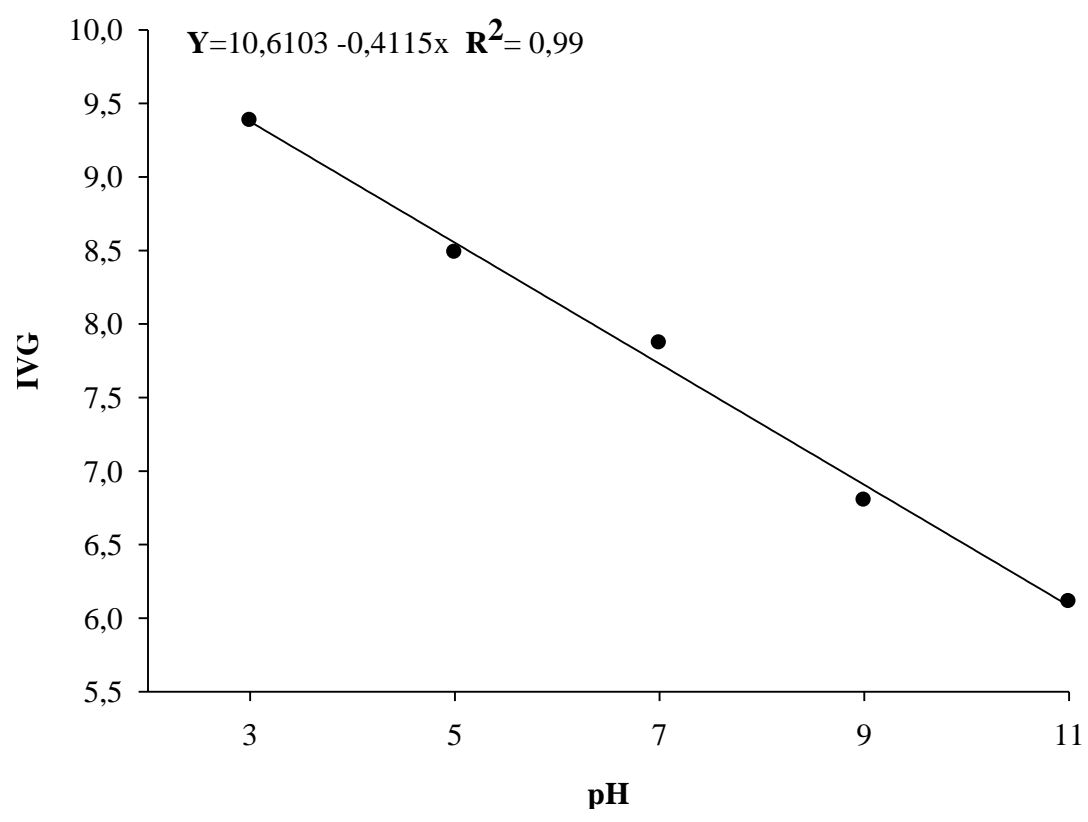

Sob condições de estresse salino pelos sais $\mathrm{CaCl}_{2}, \mathrm{NaCl}$ e $\mathrm{KCl}$, as sementes de $S$. obtusifolia (L.) H. S. Irwin \& Barneby apresentaram maior decréscimo na porcentagem de germinação entre 0 e 25 mM estabilizando nas demais concentrações osmóticas em todos os sais. Visto que a redução mais drástica foi na presença de $\mathrm{CaCl}_{2}$, onde o decréscimo mais acentuado do processo germinativo ocorreu na concentração de 50 mM (Figura 5), resultados 
estes que corroboram com os dados observados por Ferreira et al. (2013) em sementes de Cedrela odorata L, que mostrou em seu trabalho a redução do potencial germinativo dos mesmos sais nas mesmas concentrações deste estudo, havendo decréscimo mais acentuado nos potenciais a partir de $50 \mathrm{mM}$.

Figura 5. Germinação (\%) de sementes de Senna obtusifolia (L.) H. S. Irwin \& Barneby em diferentes concentrações em $\mathrm{mM}$ de $\mathrm{CaCl}_{2}$ (Cloreto de Cálcio), $\mathrm{NaCl}$ (Cloreto de Sódio) e $\mathrm{KCl}$ (Cloreto de Potássio)

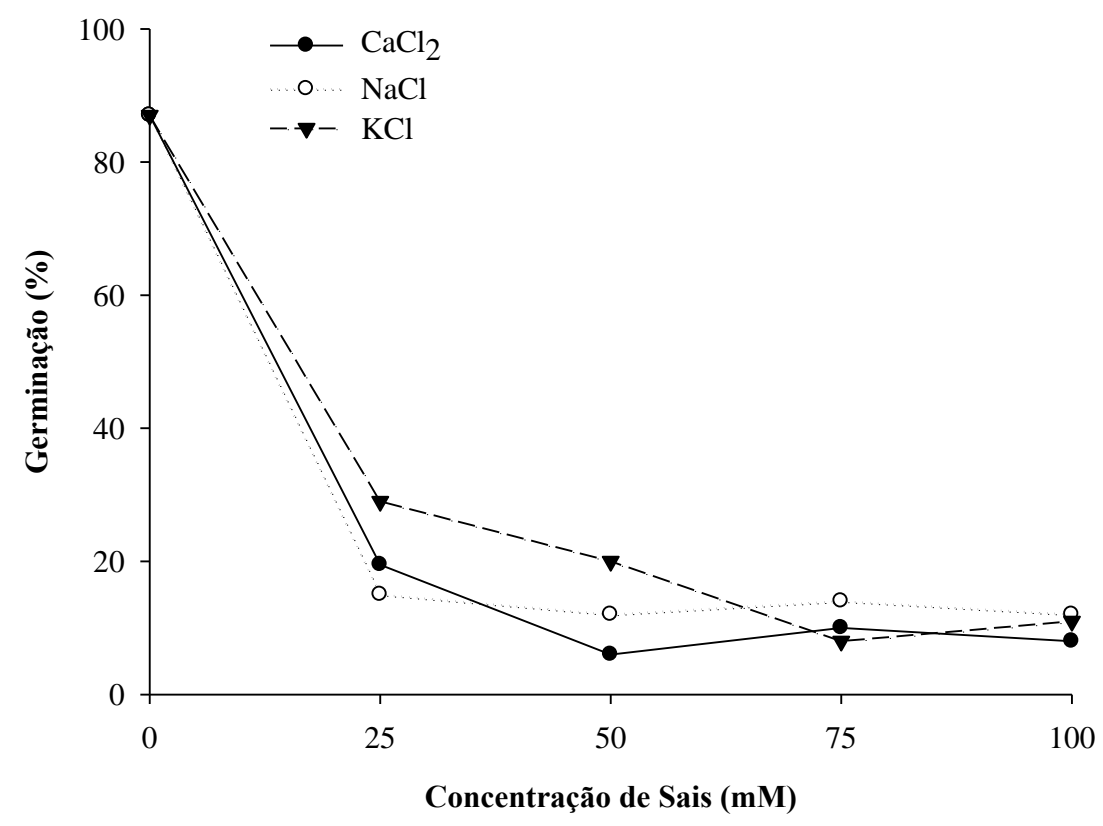

O IVG apresentou efeitos significativos isolados dos diferentes sais e concentrações, portanto o aumento na concentração salina reduziu a velocidade de germinação (Figura 6).
Essa diminuição da velocidade de germinação também foi observada por Silva et al. (2007), em sementes de Hordeum vulgare L.(cevada) sob estresse salino.

Figura 6. Índice de velocidade de germinação (IVG) de sementes de Senna obtusifolia (L.) H. S. Irwin \& Barneby em diferentes concentrações em $\mathrm{mM}$ de $\mathrm{CaCl}_{2}$ (Cloreto de Cálcio), $\mathrm{NaCl}$ (Cloreto de Sódio) e $\mathrm{KCl}$ (Cloreto de Potássio)

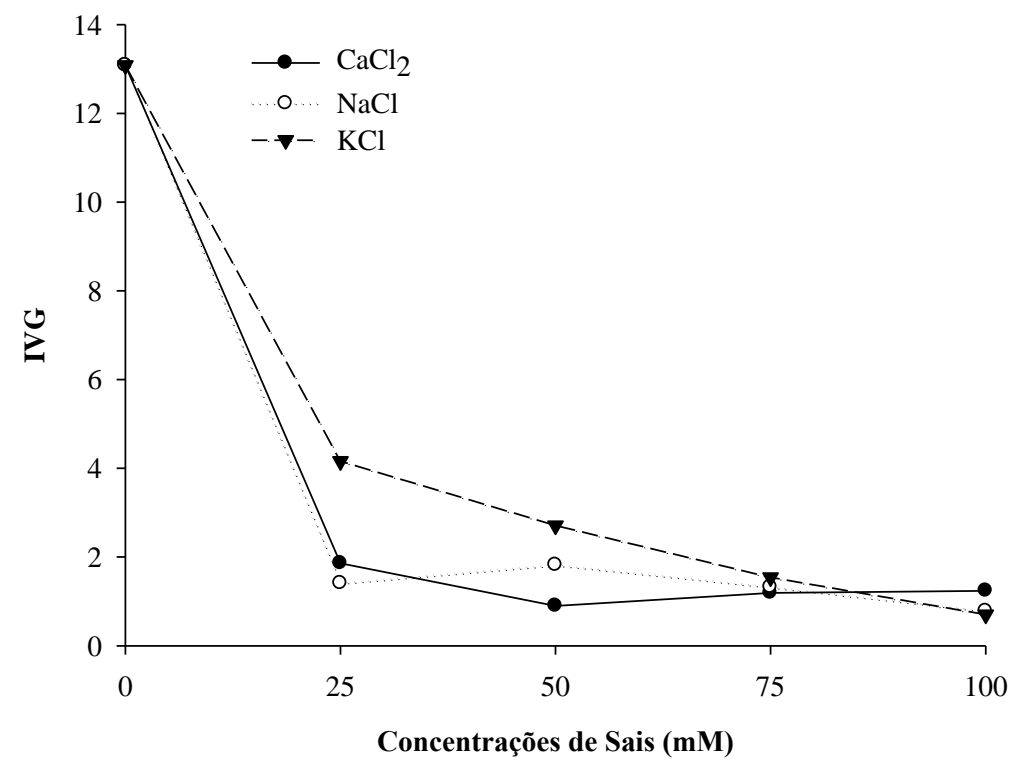




\section{CONCLUSÕES}

Para fins de controle de S. obtusifolia (L.)

H. S. Irwin \& Barneby, é essencial o conhecimento das características físicas e fisiológicas para germinação da espécie. Observou-se que as sementes apresentam maior porcentagem de germinação e IVG de sementes na temperatura de $25^{\circ} \mathrm{C}$. Condições ácidas no solo podem auxiliar na quebra de dormência de sementes de S. obtusifolia (L.) H. S. Irwin \& Barneby, sendo o tratamento com imersão em ácido sulfúrico por 10 minutos o ideal para germinação das sementes.

Após a quebra de dormência, pôde-se observar que a germinação de sementes de $S$. obtusifolia (L.) H. S. Irwin \& Barneby ocorreu em todas as faixas de $\mathrm{pH}$ analisadas, porém houve um decréscimo na porcentagem de germinação e IVG com o aumento dos níveis de $\mathrm{pH}$. Já o tratamento realizado com estresse salino afetou negativamente a germinação das sementes de $S$. obtusifolia (L.) H. S. Irwin \& Barneby, tendo os piores resultados na solução salina de $\mathrm{CaCl}_{2}$ na concentração de $50 \mathrm{mM}$.

\section{REFERÊNCIAS}

ARNON, D.I.; JOHNSON, C.M. Influence of hydrogen ion concentration on the growth fhigher plants under controlled conditions. Plant Physiology, v.17, p.525-539, 1942. https://doi.org/10.1104/pp.17.4.525

ASSUMPÇÃO, C. R. M.; PERINI, M. Superação de dormência de sementes de Senna occidentalis (L.). Natureza on line, v. 14, n. 1, p. 45-47, 2016.

BRANCALION, P. H. S.; NOVEMBRE, A. D. DA L. C.; RODRIGUES, R. R. Temperatura ótima de germinação de sementes de espécies arbóreas brasileiras. Revista Brasileira de Sementes, v. 32, n. 4, p. 015-021, 2010.

BRASIL. Ministério da Agricultura, Pecuária e Abastecimento. Regras para análise de sementes. Ministério da Agricultura, Pecuária e Abastecimento. Secretaria de Defesa Agropecuária. Brasília: Mapa/ACS, 2009. 395p.

CHIODINI, B. M.; CRUZ-SILVA, C. T. A. Efeitos da temperatura na germinação de sementes de Brachiaria brizantha cv. Marandu (Hochst. Ex A. Rich. Revista Varia Scientia Agrárias, v. 3, n. 2, p. 105-113, 2013.
CARVALHO,

N.M.;

NAKAGAWA,

J. Sementes: ciência, tecnologia e produção. 5. ed. Jaboticabal: FUNEP, 2012. 590 p.

DUTRA, A. S., MEDEIROS FILHO, S.; TEÓFILO, E. M.; DINIZ, F. O. Germinação de sementes de Senna siamea (Lam.) H. S. Irwin \& Barneby Caesalpinoideae. Revista Brasileira de Sementes, v. 29, n. 1, p. 160-164, 2007. https://doi.org/10.1590/\$0101-

$\underline{31222007000100022}$

ERASMO, E. A. L.; TERRA, M. A.; DOMINGOS, V. D.; MARTINS, C. C.; COSTA, N. V. da. Superação da dormência em sementes de Murdannia nudiflora (L.) Brenan. Acta Scientiarum Agronomy. v. 30, n. 2, p. 273-277, 2008.

GORAI, M.; NEFFATI, M. Germination responses of Reaumur vermiculata to salinity and temperature. Annals of Applied Biology. v.151, p. 53-59, 2007. https://doi.org/10.1111/i.17447348.2007.00151.x

LIMA, J. D. et al. Efeito da temperatura e do substrato na germinação de sementes de Caesalpinia ferrea Mart. ex Tul. (Leguminosae, Caesalpinoideae). Revista Árvore, Viçosa, v. 30, n. 4, p. 513-518, 2006.

MARANHO, Á. S.; PAIVA, A. V. de. Superação de dormência tegumentar em sementes de Senna silvestris (Vell.) H. S. Irwin \& Barneby. Revista Biotemas, v. 25, n.2, 2012.

MAYEUX, H.S.; SCIFRES, C.J. Germination golden weed seed. J. Range Management, v.31, p.371374, 1978. https://doi.org/10.2307/3897362

MOREIRA, H. J. C.; BRAGANÇA, H. B. N. Manual de Identificação de Plantas Infestantes: Hortifrúti. Campinas: FMC Agricultural Products, 2011. p. 322-323.

PARREIRA, M. C.; CARDOZO, N. P.; GIANCOTTI, P. R. F.; ALVES, P. L. A. C. Germinação de sementes de melão-de-são-caetano sob variação de água, luz e temperatura. Bioscience Journal, v. 27, n. 3, p. 363-370, 2011.

PEEL, M. C.; FINLAYSON, B. L.; MCMAHON, T. A. Update world map of the Köppen-Geiger climate classification. Hydrology and Earth System 
Sciences Discussions, European Geosciences Union, v. 11, p. 1633-1644, 2007.

PIVETA, G.; MENEZES, V. O.; PEDROSO, D. C.; MUNIZ, M. F. B.; BLUME, E. WIELEWICKI, A. P. Superação de dormência na qualidade de sementes e mudas: influência na produção de Senna multijuga (L. C. Rich) Irwin \& Barneby. Acta Amazonica, v.40, n.2, p.281-288, 2010. https://doi.org/10.1590/S0044-

$\underline{59672010000200006}$

RODRIGUES, A. P. D. C.; LAURA, V. A.; PAREIRA, S. R.; SOUZA, A. L.; FREITAS, M. E. Temperatura de germinação em sementes de estilosantes. Revista Brasileira de Sementes, v. 32, n. 4, p.166-173, $2010 . \quad$ https://doi.org/10.1590/S0101$\underline{31222010000400019}$

SILVA, R. N.; LOPES, N. F.; MORAES, D. M. Physiological quality of barley seeds submitted to saline stress. Revista Brasileira de Sementes, v.29, n.1, p.40-44, 2007. https://doi.org/10.1590/S0101$\underline{31222007000100006}$

SOUZA, S. C. A.; AMARAL, V. B.; MORAIS, F.; LUZ, G. R.; NUNES, Y. R. F.; REIS-JÚNIOR, R. Escarificação de sementes de Senna espectabilis (DC) Irwin Et Barn. (Fabaceae-Caesalpinioideae). In: SIMPÓSIO NACIONAL DE CERRADO e II SIMPÓSIO INTERNACIONAL DE SAVANAS TROPICAIS, 9. Brasília. Anais... Brasília: Embrapa, 2008. 7 p.

TOPANOTTI, L.R.; PEREIRA, P.H.; BECHARA, F.C. Germinação de sementes de Senna obtusifolia (L.) H. S. Irwin \& Barneby (fabaceae) visando a restauração de áreas degradadas. Ci. Biol. Saúde, v.20, n.2, p. 125-129, 2014.

VAZ-DE-MELO, A.; AFFÉRRI, F. S.; DOTTO, M. A.; PELUZIO, J. M.; SANTOS, G. R.; CARVALHO, E. V. Reação de híbridos de milho à Curvularia ssp, sob dois níveis de adubação com nitrogênio, no sul do Tocantins. Scientia Agraria, v. 11, n. 2, p. 149-154, 2010. https://doi.org/10.5380/rsa.v11i2.16590

VIVIAN, R.; GOMES JR., F.G.; CHAMMA, H.M.C.P.; SILVA, A.A.; FAGAN, E.B.; RUIZ, S.T. Efeito da luz e da temperatura na germinação de Alternathera tenella, Conyza bonariensis e Digitaria ciliaris. Planta Daninha, v. 26, n. 3, p. 507-513, 2008a.
https://doi.org/10.1590/S0100$\underline{83582008000300005}$

VIVIAN, R.; SILVA, A. A.; GIMENES, Jr. M.; FAGON, E.B.; RUIZ, S. T.; LABONIA, V. Dormência em sementes de plantas daninhas como mecanismo de sobrevivência - breve revisão. Planta Daninha, v. 26 , n. 3 , p. 695-706, 2008b. https://doi.org/10.1590/s0100$\underline{83582008000300026}$

YAMASHITA, O.M.; GUIMARÃES, S.C.; SILVA, J.L.; CARVALHO, M.A.C.; CAMARGO, M.F. Fatores ambientais sobre a germinação de Emilia sonchifolia. Planta Daninha, v. 27, n. 4, p. 673681, 2009. https://doi.org/10.1590/S0100$\underline{83582009000400005}$

YAMAUTI, M.S.; PAVANI, M.C.M.D.; ALVES, P.L.C.A.; MORO, F.V. Efeito de fatores ambientais sobre a germinação de agriãozinho (Synedrellopsis grisebachii). Científica, v.40, n.2, p. 150-155, 2012.

Recebido para publicação em 14/03/2017

Revisado em 20/07/2017

Aceito em 22/03/2018 